\title{
Studi Kinerja Guru Lulusan Program Studi Pendidikan Kimia Universitas Negeri Yogyakarta di Daerah Istimewa Yogyakarta
}

\author{
Kresni Dwi Jayanti ${ }^{1} *$, S. Senam ${ }^{1}$ \\ ${ }^{1}$ Program Studi Pendidikan Kimia, Program Pascasarjana, Universitas Negeri Yogyakarta. \\ Jalan Colombo No. 1, Karangmalang, Yogyakarta 55281, Indonesia \\ * Corresponding Author. Email: xriztal_sweet@yahoo.com \\ Received: 14 January 2017; Revised: 8 May 2017; Accepted: 18 May 2017
}

\begin{abstract}
Abstrak
Penelitian ini merupakan penelitian survei yang bertujuan untuk:(1) mengetahui kinerja guru lulusan Program Studi Pendidikan Kimia FMIPA UNY yang mengajar di SMA dan SMK di Daerah Istimewa Yogyakarta ditinjau dari kompetensi pedagogik, kepribadian, sosial dan profesional dan(2) mengetahui kinerja guru lulusan Program Studi Pendidikan Kimia FMIPA UNY dalam perencanaan, pelaksanaan dan penilaian pembelajaran di SMA dan SMK di Daerah Istimewa Yogyakarta (DIY). Penelitian ini merupakan penelitian survei dengan populasi penelitian guru kimia di 3 SMA dan 14 SMK di DIY. Pengumpulan data dilakukan dengan observasi, angket dan wawancara. Hasil penelitian menunjukkan bahwa (1) kinerja guru kimia pada kompetensi pedagogik, kepribadian, sosial dan profesional memiliki kriteria baik. (2) kinerja guru kimia hasil observasi mengenai perencanaan, pelaksanaan dan penilaian pembelajaran memiliki kriteria baik. Hasil tersebut menunjukkan bahwa kinerja guru kimia lulusan program studi pendidikan kimia UNY di SMA dan SMK di DIY secara umum adalah baik.
\end{abstract}

Kata Kunci: kinerja guru, kompetensi guru

\section{A Performance Study of the Teachers Graduating from the Chemistry Educational Program of the State University of Yogyakarta Special Region}

\begin{abstract}
This study is a survey which aims to: (1) determine the performance of the teachers in secondary school in Yogyakarta Special Region who graduated from UNY Chemistry Educational Program Faculty of Mathematics and Science, in term of the pedagogic, personality, social and professional competences. (2) determine the performance of the teachers in secondary school in Yogyakarta Special Region who graduated from UNY Chemistry Educational Program Faculty of Mathematics and Science, in term of planning, implementation, and assessment of teaching The population of this survey was chemistry teachers at some of high school and vocational school in Yogyakarta Special Region. Data collection instruments are observations, questionnaires, and interviews. The results of this study showed that (1) the performance of chemistry teachers on pedagogical, personality, social and professional has a good criteria.(2) the performance of chemistry teacher in planning, implementation, and assessment of learning has a good criteria. This result showed that the performance of the teachers in secondary school in Yogyakarta Special Region who graduated from UNY Chemistry Educational Program Faculty of Mathematics and Science generally is good.
\end{abstract}

Keywords: teacher's performance, teacher's competence

How to Cite: Jayanti, K., \& Senam, S. (2017). Studi kinerja guru lulusan Program Studi Pendidikan Kimia Universitas Negeri Yogyakarta di Daerah Istimewa Yogyakarta. Jurnal Inovasi Pendidikan IPA, 3(1), 63-69. doi:http://dx.doi.org/10.21831/jipi.v3i1.13686

Permalink/DOI: http://dx.doi.org/10.21831/jipi.v3i1.13686 


\section{Jurnal Inovasi Pendidikan IPA, 3 (1), 2017 - 64}

Kresni Dwi Jayanti, S. Senam

\section{PENDAHULUAN}

Pendidikan nasional berupaya untuk membangun masyarakat yang memiliki ilmu pengetahuan, mampu mengembangkan potensi diri dan mampu menghadapi tantangan di masa mendatang. Undang-undang Sisdiknas nomor 20 tahun 2003 menjelaskan bahwa pendidikan nasional berfungsi untuk mengembangkan kemampuan dan membentuk watak serta peradaban bangsa yang bermartabat dalam rangka mencerdaskan kehidupan bangsa, untuk itu diperlukan pembaharuan pendidikan secara terencana, terarah, dan berkesinambungan (Presiden Republik Indonesia, 2003).

Pemerintah memberi kesempatan kepada masyarakat untuk meningkatkan kualitas pendidikan melalui pendidikan formal. Pendidikan formal yang diselenggarakan di sekolah memiliki beberapa komponen meliputi guru, peserta didik dan kurikulum. Guru merupakan komponen utama dalam proses pembelajaran di sekolah untuk menentukan keberhasilan peserta didiknya. Peserta didik berkewajiban untuk mengembangkan potensi dirinya dengan bimbingan dari guru. Guru membutuhkan sebuah alat sebagai pedoman dalam membimbing peserta didik di sekolah yaitu kurikulum. Kurikulum merupakan seperangkat rencana dan pengaturan mengenai tujuan, isi, dan bahan pelajaran serta cara yang digunakan sebagai pedoman penyelenggaraan kegiatan pembelajaran untuk mencapai tujuan pendidikan tertentu (Presiden Republik Indonesia, 2003).

Pemerintah bertanggung jawab dalam menyelenggarakan program pendidikan yang bertujuan untuk menghasilkan guru yang berkualitas. Kualitas guru selalu diupayakan oleh pemerintah melalui persyaratan kualifikasi pendidikan maupun kegiatan lain seperti pendidikan dan latihan (diklat), penataran dan keterlibatan guru dalam berbagai seminar untuk menambah wawasan yang mampu meningkatkan kompetensi pedagogik dan akademik.

Pemerintah telah menetapkan standar kualifikasi akademik dan kompetensi guru yang diatur dengan Peraturan Menteri (Permen) nomor 16 tahun 2007. Setiap guru wajib memenuhi standar kualifikasi akademik dan kompetensi guru yang berlaku secara nasional. Kualifikasi akademik guru pada satuan Standar kompetensi guru dikembangkan secara utuh dari empat kompetensi utama, yaitu kompetensi pedagogik, kepribadian, sosial, dan profesional. Keempat kompetensi tersebut diharapkan terintegrasi dan terealisasi dalam bentuk kinerja guru (Menteri Pendidikan Nasional, 2007).

Kinerja guru dalam proses pembelajaran dipengaruhi oleh lingkungan kerja yang kondusif karena guru merasa nyaman dalam melaksanakan tugas mengajarnya, sehingga berpengaruh terhadap proses pembelajaran di sekolah. Lingkungan kerja meliputi kemampuan manajerial kepala sekolah dan lingkungan sekitar. Kepala sekolah dapat memberikan arahan serta bimbingan kepada guru agar memiliki kinerja yang baik, dan profesional dalam menjalankan tugasnya.

Undang-undang nomor 14 tahun 2005 tentang guru dan dosen menyatakan bahwa guru mempunyai kedudukan sebagai tenaga profesional yang berfungsi untuk meningkatkan martabat dan peran guru sebagai agen pembelajaran untuk meningkatkan mutu pendidikan nasional (Presiden Republik Indonesia, 2005). Tingkat profesionalisme guru di lapangan saat ini masih bervariasi. Hal ini ditunjukkan oleh hasil penelitian yang dilakukan oleh Suparwoto, Prasetya, Mundilarto, Sukardjo, \& Projosantoso (2010) mengenai kinerja guru IPA SD, SMP, dan SMA pascasertifikasi yang menunjukan bahwa aspek kompetensi profesional guru SMA paling menonjol, berikutnya guru SD dan SMP.Untuk kompetensi pedagogik, kepribadian dan sosial diperoleh hasil bahwa guru IPA tingkat SMP dan SD paling menonjol, yang diikuti oleh guru IPA SMA. Aspek yang berkaitan dengan kinerja lebih mengutamakan aktivitas guru yang bersifat prosedural, sedangkan yang berkaitan dengan pengembangan kreativitas belum mendapat perhatian di kalangan guru IPA SD, SMP, dan SMA (Suparwoto et al., 2010). Untuk itu perlu disadari bahwa profesionalisme guru sangat diperlukan agar proses pembelajaran dapat berlangsung dengan baik.

Tabel 1.Jumlah Guru di Provinsi Daerah Istimewa Yogyakarta

\begin{tabular}{lcc}
\hline Jenjang & Jumlah Guru & Persentase (\%) \\
\hline TK & 8.013 & 15,04 \\
SD & 21.647 & 40,64 \\
SMP & 10.260 & 19,26 \\
SLB & 1.131 & 2,12 \\
SMA & 5.302 & 9,95 \\
SMK & 6.912 & 12,98 \\
\hline Total & $\mathbf{5 3 . 2 6 5}$ & $\mathbf{1 0 0}$ \\
\hline \multicolumn{3}{c}{ (Warso, 2012) }
\end{tabular}

Berdasarkan data yang ada di Lembaga Penjamin Mutu Pendidikan (LPMP) bahwa di propinsi DIY memiliki guru yang ditugaskan 


\section{Jurnal Inovasi Pendidikan IPA, 3 (1), 2017 - 65}

Kresni Dwi Jayanti, S. Senam

mulai dari jenjang TK sampai pendidikan menengah berjumlah 53.265 orang (Warso, 2012). Data mengenai jumlah guru secara rinci disajikan pada Tabel 1.

Guru tersebut tersebar di sekolah negeri maupun swasta di 5 Daerah Tingkat Dua yaitu Kota Yogyakarta, Kabupaten Sleman, Kabupaten Gunungkidul, Kabupaten Bantul, dan Kabupaten Kulon Progo. Tingkat penyebaran guru di sekolah tidak merata, sehingga di daerah tertentu kekurangan guru. Hal ini ditunjukkan oleh adanya guru yang mengajar tidak sesuai dengan bidangnya. Menu-rut Sugeng Mardiyono dalam Sukanti, Sumarsih, Siswanto, \& Widayati (2008) kualifikasi akade-mik guru-guru ternyata masih memprihatinkan. Kenyataan yang terjadi pada saat ini keadaan guru hampir 29\% guru pada jenjang pendidikan menengah masih belum memiliki ijazah S-1. Artinya hampir 29\% guru sekolah menengah masih underqualified. Sementara itu guru yang merupakan lulusan LPTK yang mengajar bukan bidangnya pada jenjang sekolah menengah berkisar antara $17 \%$ sampai $19 \%$. Selain itu masih banyak guru pada jenjang pendidikan menengah belum memiliki akta mengajar.

Guru seharusnya memiliki kualifikasi pendidikan sesuai dengan bidang studi yang diampu. Salah satu bidang studi di SMA atau SMK adalah kimia. Kompetensi guru bidang studi kimia diharapkan mampu dimiliki sesuai dengan bidang tugas yang diembannya. Guru kimia yang mengajar di SMA atau SMK di DIY tinggi di Indonesia, antara lain dari Program Studi Pendidikan Kimia Fakultas MIPAUNY. Data UNY tentang guru lulusan Program Studi Pendidikan Kimia yang bekerja di DIY belum lengkap sehingga data lulusan sudah bekerja sebagai guru di Yogyakarta dapat diperoleh melalui Dinas Pendidikan di setiap kabupaten atau melalui Lembaga Penjamin Mutu Pendidikan. Kompetensi yang diperoleh selama kuliah diharapkan dapat dimanfaatkan secara optimal.Sehingga untuk mengetahui kompetensi yang dimiliki oleh guru kimialulusan UNY, maka pada penelitian ini akan dibahas mengenai kinerja guru lulusan Program Studi Pendidikan Kimia UNY yang bekerja sebagai guru di DIY.

\section{METODE}

Penelitian ini adalah penelitian survei yang dilakukan dengan cara mengumpulkan informasi tentang sampel penelitian melalui berbagai instrumen. Penelitian ini dilaksanakan pada bulan Maret sampai dengan Juni 2013 di
Sekolah Menengah Atas dan Sekolah Menengah Kejuruan di wilayah Provinsi Daerah Istimewa Yogyakarta.

Populasi dalam penelitian ini dilakukan dengan purposive sampling, dimana penelitian ini ditujukan untuk melihat kompetensi guru kimia lulusan Program Studi Pendidikan Kimia FMIPA UNY tahun 2002 sampai dengan 2009 yang bekerja di DIY. Guru kimia yang dimaksud tersebar di SMA dan SMK di lima Daerah Tingkat Dua yaitu 2 guru di Kota Yogyakarta, 4 guru di Kabupaten Sleman, 1 guru di Kabupaten Bantul, 7 guru di Kabupaten Gunungkidul dan 3 guru di Kabupaten Kulon Progo).

Data dikumpulkan berupa lembar angket yang berisi pertanyaan tentang kinerja guru di sekolah dan menyertakan nama sekolah, nama guru, serta nama sumber informasi untuk memudahkan dalam pengelompokan data. Setiap guru dinilai oleh 4 kelompok penilai yaitu kepala sekolah sebagai atasan, dirinya sendiri, guru sejawat dan peserta didik yang sedang diberi pelajaran oleh guru tersebut. Data mengenai guru kimia diperoleh dengan mencocokkan data dari Lembaga Pusat Penjamin Mutu Pendidikan Yogyakarta dengan data alumni di UNY.

Tabel 2 menyajikan teknik pengumpulan data yang digunakan dalam penilaian kinerja guru.

Tabel 2. Teknik Pengumpulan Data Untuk Penilaian Kinerja Guru

\begin{tabular}{|c|c|c|}
\hline $\begin{array}{l}\text { Jenis } \\
\text { Data }\end{array}$ & Jenis Informasi & Teknik \\
\hline \multirow[t]{4}{*}{$\begin{array}{l}\text { Kinerja } \\
\text { guru }\end{array}$} & $\begin{array}{l}\text { Kepala sekolah atau wakil } \\
\text { kepala sekolah bagian } \\
\text { kurikulum }\end{array}$ & $\begin{array}{l}\text { Wawancara, } \\
\text { angket }\end{array}$ \\
\hline & $\begin{array}{l}\text { Guru subjek atau sampel } \\
\text { penelitian }\end{array}$ & $\begin{array}{l}\text { Wawancara, } \\
\text { observasi } \\
\text { dan } \\
\text { dokumentasi }\end{array}$ \\
\hline & $\begin{array}{l}\text { Perwakilan guru sejawat } \\
\text { masing-masing sekolah } \\
\text { berjumlah } 2 \text { orang guru } \\
\text { kimia }\end{array}$ & $\begin{array}{l}\text { Wawancara } \\
\text { dan angket }\end{array}$ \\
\hline & Peserta didik & Angket \\
\hline
\end{tabular}

\section{Teknik Analisis Data}

Pengumpulan data kompetensi dan kinerja guru yang digunakan dalam penelitian ini berupa dokumentasi, observasi, angket dan wawancara. Berdasarkan hasil dari lembar observasi dan lembar angket diperoleh hasil mengenai kompetensi dan kinerja guru. Data mengenai kinerja guru diisi oleh kepala sekolah, guru yang bersangkutan, guru sejawat dan peserta didik. 


\section{Jurnal Inovasi Pendidikan IPA, 3 (1), 2017 - 66}

Kresni Dwi Jayanti, S. Senam

Dokumentasi

Pengumpulan data dengan dokumentasi dalam penelitian ini berupaya mengumpulkan data yang terkait dengan pembelajaran yang berhubungan dengan aktivitas guru dalam mengajar.

\section{Observasi}

Lembar observasi menyajikan pilihan jawaban Ya atau Tidak. Data yang diperoleh dari lembar observasi didasarkan pada jumlah tanda $(\sqrt{ })$ untuk pengamatan komponen yang tampak dan tanda (-) untuk pengamatan komponen yang tidak tampak. Skor untuk setiap komponen pada setiap pertemuan dihitung. Adapun persentase keterlaksanaan kegiatan pembelajaran yang dilakukan oleh guru menggunakan rumus sebagai berikut:

$\%$ Keterlaksanaan $=\frac{\text { Banyaknya Deskriptor yang Terlaksana }}{\text { Banyaknya Deskriptor }} \times 100 \%$

Aktivitas tersebut dapat mewakili kegiatan yang dilakukan oleh guru yang diteliti berupa perencanaan, pelaksanaan dan penilaian dalam pembelajaran di kelas.

Angket

Angket disusun dengan 4 pilihan jawaban yaitu: sangat setuju (skor 4), setuju (skor 3), tidak setuju (skor 2) dan sangat tidak setuju (skor 1) yang berisi tentang kinerja guru di sekolah. Angket yang dibuat harus memenuhi syarat terkait dengan validitas dan reliabilitas serta telah melalui proses validasi yang dilakukan oleh ahli. Skor yang diperoleh kemudian dikonversikan menjadi nilai pada skala 4 dengan acuan Tabel 3 yang dikutip dari (Azwar, 2010, p. 163).

Tabel 3.Konversi Skor Ke Nilai Skala Empat

\begin{tabular}{cc}
\hline Interval Skor & Kategori \\
\hline $\mathbf{X}>\mathrm{x}_{\mathrm{i}}+1,5 \mathrm{SB}_{\mathrm{i}}$ & Sangat Baik \\
$\mathrm{X}_{\mathrm{i}}<\mathbf{X} \leq \mathrm{x}_{\mathrm{i}}+1,5 \mathrm{SB}_{\mathrm{i}}$ & Baik \\
$\mathrm{x}_{\mathrm{i}}-1,5 \mathrm{SB}_{\mathrm{i}}<\mathbf{X} \leq \mathrm{x}_{\mathrm{i}}$ & Cukup \\
$\mathbf{X} \leq \mathrm{x}_{\mathrm{i}}-1,5 \mathrm{SB}_{\mathrm{i}}$ & Kurang \\
\hline
\end{tabular}

Keterangan:

$\mathrm{x}_{\mathrm{i}}=$ Rerata skor ideal

$=\frac{1}{2}($ skor maksimal + skor minimal ideal $)$

$\mathrm{SBi}=$ Simpangan baku ideal

$=\frac{1}{6}($ skor maksimal ideal - skor minimal ideal $)$

$\mathbf{X}=$ Skor aktual (skor yang dicapai)

Skor maksimal ideal $=\sum$ butir kriteria $\mathrm{x}$ skor

tertinggi

Skor terendah ideal $=\sum$ butir kriteria $\mathrm{x}$ skor terendah
Wawancara

Lembar wawancara berisi pertanyaan yang diajukan kepada kepala sekolah, guru sejawat dan guru kimia lulusan UNY yang terkait dengan kinerja guru kimia lulusan UNY di sekolah.

\section{HASIL DAN PEMBAHASAN}

\section{Analisis Data Kompetensi Pedagogik}

Penilaian terhadap kompetensi pedagogik dilakukan oleh kepala sekolah, guru sejawat dan peserta didik, yang diilustrasikan dalam Gambar 1.

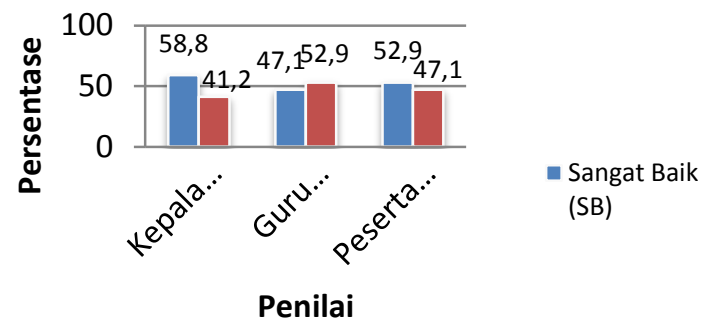

Gambar 1. Diagram Kompetensi Pedagogik Berdasarkan Penilaian Kepala Sekolah, Guru Sejawat, dan Peserta Didik

Gambar 1 menunjukkan bahwa guru kimia memiliki kompetensi pedagogik yang sangat baik berdasarkan penilaian kepala sekolah dan peserta didik, menurut guru sejawat memiliki kriteria baik. Hal ini menunjukkan bahwa guru kimia mampu mengelola kelas dengan baik. Pengelolaan kelas meliputi pemahaman terhadap kondisi peserta didik, perancangan dan pelaksanaan pembelajaran, penilaian hasil belajar dan aktualisasiberbagai potensi yang dimiliki oleh peserta didik.

\section{Analisis Data Kompetensi Kepribadian}

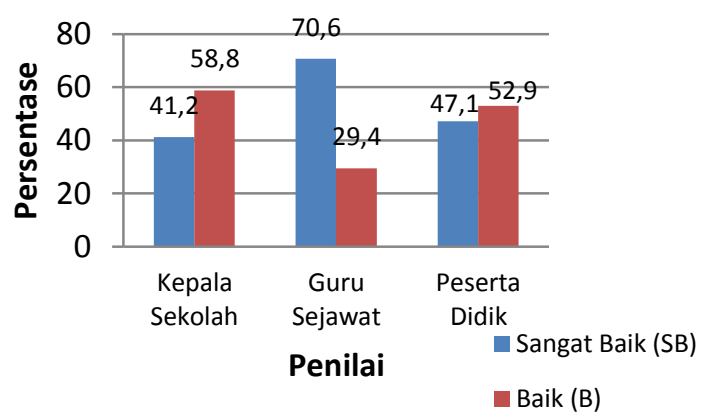

Gambar 2. Diagram Kompetensi Kepribadian Berdasarkan Penilaian Kepala Sekolah, Guru Sejawat dan Peserta Didik 
Kompetensi kepribadian guru kimia berdasarkan penilaian kepala sekolah, guru sejawat dan peserta didik diilustrasikan pada Gambar 2.

Secara umum kompetensi kepribadian yang dimiliki oleh guru kimia berdasarkan penilaian guru sejawat memiliki kriteria sangat baik, sedangkan berdasarkan penilaian kepala sekolah dan peserta didik memiliki kriteria baik. Guru yang memiliki kompetensi kepribadian yang baik menunjukkan etos kerja, tanggung jawab yang tinggi, rasa bangga menjadi guru, rasa percaya diri, menjunjung tinggi kode etik profesi guru, serta mampu menjadi teladan yang baik bagi peserta didik.Sehingga kompetensi kepribadian guru mampu mengembangkan karakter peserta didik.

\section{Analisis Data Kompetensi Sosial}

Diagram penilaian kompetensi sosial oleh kepala sekolah, guru sejawat dan peserta didik dapat dilihat pada Gambar 3.

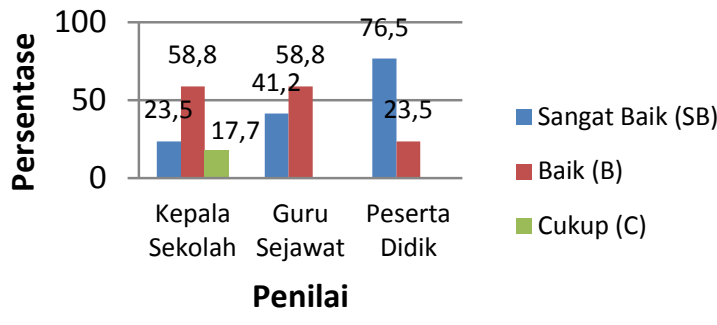

Gambar 3.Diagram Kompetensi Sosial Berdasarkan Penilaian Kepala Sekolah, Guru Sejawat dan Peserta Didik

Kompetensi sosial guru kimia berdasarkan penilaian guru sejawat dan peserta didik rata-rata memiliki kemampuan yang baik. Berdasarkan penilaian dari kepala sekolah menunjukkan bahwa kompetensi sosial yang dimiliki oleh guru kimia sebanyak 17,7\% memiliki kriteria cukup. Data ini menunjukkan bahwa kemampuan berkomunikasi secara efektif dengan peserta didik, pendidik, tenaga kependidikan, orangtua/wali peserta didik, dan masyarakat sekitar berdasarkan penilaian guru sejawat dan peserta didik rata-rata baik. Berdasarkan penilaian kepala sekolah menunjukkan bahwa kemampuan berkomunikasi guru kimia perlu ditingkatkan.Kompetensi sosial ini sangat penting bagi guru, karena komunikasi dengan warga sekolah akan membantu guru dalam menjalankan tugasnya.

\section{Analisis Data Kompetensi Profesional}

Gambar 4 menunjukkan hasil penilaian kompetensi profesional oleh kepala sekolah dan guru sejawat.

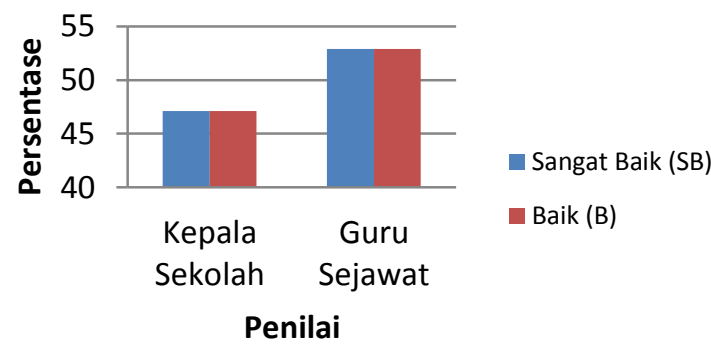

\section{Gambar 4.Diagram Kompetensi \\ ProfesionalBerdasarkan Penilaian Kepala Sekolah dan Guru Sejawat}

Penilaian kompetensi profesional ini hanya dilakukan oleh kepala sekolah dan guru sejawat. Peserta didik tidak diikutsertakan dalam penilaian kompetensi profesional guru kimia, karena penilaian kompetensi ini berkaitan dengan penguasaan materi pembelajaran.Untuk itu penilaian kompetensi profesional ini hanya dilakukan oleh orang yang seprofesi. Berdasarkan hasil analisis data terlihat bahwa guru kimia memiliki kriteria baik. Hal ini menunjukkan bahwa guru kimia memiliki kemampuan penguasaan materi pembelajaran secara luas dan mendalam yang memungkinkan untuk membimbing peserta didik untuk memenuhi standar kompetensi yang ditetapkan dalam Standar Nasional Pendidikan.

\section{Kinerja Guru Berdasarkan Hasil Observasi}

Data mengenai kinerja guru diperoleh melalui observasi langsung di sekolah. Observasi dilaksanakan ketika guru sedang mengajar di kelas. Observer mengamati kegiatan yang dilakukan oleh guru tersebut di dalam kelas. Observasi ini dibuat berdasarkan tiga indikator yang terkait dengan kemampuan dalam melakukan perencanaan pembelajaran, pelaksanaan kegiatan pembelajaran, serta penilaian pembelajaran.

Hasil pengamatan menunjukkan bahwa perencanaan pembelajaran yang dilakukan oleh guru kimia memiliki kriteria sangat baik sebanyak 6 guru $(35,3 \%)$ dan kriteria baik sebanyak 11 guru $(64,7 \%)$.

Perencanaan pembelajaran yang dilakukan oleh guru kimia memiliki kriteria baik. Data ini menunjukkan bahwa guru tersebutmemiliki kemauan dan kesadaran untuk merencanakan 
pembelajaran antara lain dalam bentuk mempersiapkan program semester, menyusun Rencana Pelaksanaan Pembelajaran dan silabus, menyusun bahan pengajaran, menentukan metode pengajaran yang sesuai, menentukan sumber pengajaran/buku sesuai dengan materi yang disampaikan, serta menentukan media pembelajaran. Penyusunan bahan ajar dan penentuan media pembelajaran rata-rata dengan kriteria kurang. Lemahnya penyusunan bahan ajar ini dikarenakan adanya sumber pembelajaran yang lebih praktis yang berupa buku paket atau buku acuan lain. Untuk itu guru cenderung menggunakan buku tersebut daripada harus menyusun bahan ajar sendiri.

Kualitas pelaksanaan pembelajaran yang dilakukan oleh guru kimia memiliki kriteria sangat baik sebanyak 7 guru $(41,2 \%)$ dan kriteria baik sebanyak 10 guru $(58,8 \%)$. Berdasarkan hasil analisis data menunjukkan bahwa ratarata guru memiliki kriteria baik dalam pelaksanaan pembelajaran. Kekurangan yang masih dimiliki oleh guru dalam pelaksanaan pembelajaran antara lain dalam memimpin doa, menggunakan LKS, menggunakan media pembelajaran dan mengakhiri kegiatan pembelajaran dengan tepat waktu.

Kegiatan guru kimia dalam memimpin doa baik sebelum maupun sesudah pembelajaran rata-rata tidak dilakukan.Guru melakukannya sebelum pelajaran dimulai yaitu pada jam pertama dan jam terakhir. Penggunaan LKS oleh guru kimia masih kurang. Guru lebih banyak menggunakan buku paket dalam kegiatan pembelajaran. Penggunaan media pembelajaran juga masih kurang. Guru kimia lebih memilih menjelaskan secara langsung tanpa bantuan alat peraga ataupun media berbantuan Teknologi Informasi dan Komunikasi (TIK). Sebanyak 41,2 \% guru kimia telah menggunakan media baik alat peraga maupun media berbasis TIK ketika mengajar. Dengan bantuan media ini membuat peserta didik lebih aktif dan kreatif selama kegiatan pembelajaran, sehingga pembelajaran menjadi lebih menyenangkan dan mudah dimengerti oleh peserta didik. Hasil observasi menunjukkan bahwa guru yang menggunakan media berbasis TIK cenderung hanya menjelaskan pelajaran yang disusun tanpa memberikan soal maupun pertanyaan pada peserta didik sehingga suasana kelas menjadi tidak kondusif. Penggunaan media berbasis TIK sebenarnya memudahkan guru dalam memberikan materi pembelajaran, namun harus dimodifikasi dengan pemberian pertanyaan kepada peserta didik. Guru kimia rata-rata mengakhiri pembelajaran dengan kurang tepat waktu. Kegiatan pembelajaran di kelas berlangsung lebih lama karena guru merasa materi yang diajarkan tidak dapat ditunda, sehingga guru yang bersangkutan memerlukan waktu perpanjangan untuk menyelesaikannya.

Observasi terhadap penilaian pembelajaran memiliki kriteria sangat baik sebanyak 11 guru $(64,7 \%)$ dan kriteria baik sebanyak 10 guru $(35,3 \%)$. Rata-rata kualitas penilaian pembelajaran yang dilakukanoleh guru kimia memiliki kriteria baik. Kegiatan yang masih kurang dilakukan oleh guru yaitu pemberian pretes dan menilai tugas yang dikumpulkan oleh peserta didik maupun ketika peserta didik mau mengerjakan tugas di depan kelas. Guru kimia lebih memilih menyelenggarakan ulangan harian daripada pretes. Sebanyak $47 \%$ guru tidak memberikan penilaian ketika peserta didik mengerjakan tugas, walaupun sebanyak $53 \%$ guru memberikan penilaian terhadap tugas yang dikumpulkan oleh peserta didik. Penilaian tugas ini berguna untuk memberikan motivasi kepada peserta didik agar terus meningkatkan prestasi belajarnya. Kinerja guru kimia hasil observasi diilustrasikan pada Gambar 5.

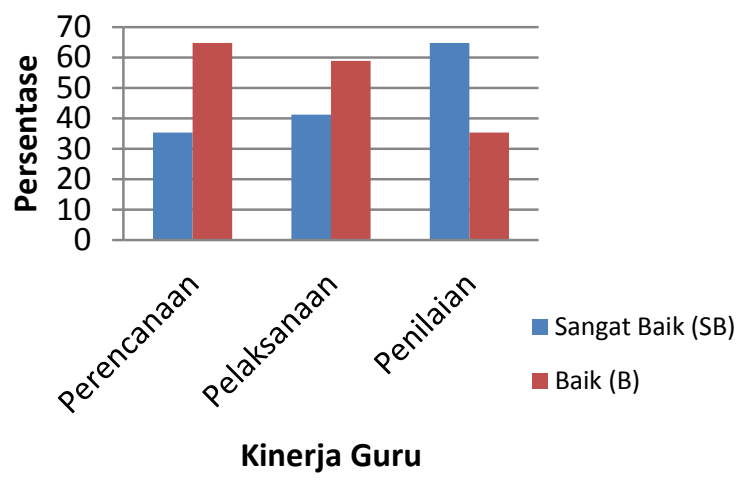

Gambar 5.Data Perencanaan, Pelaksanaan dan Penilaian Pembelajaran Guru Kimia Hasil Observasi

\section{Penilaian Kinerja Guru Berdasarkan Wawancara}

Wawancara dilakukan untuk melakukan cross check mengenai keadaan guru kimia. Kegiatan ini dilakukan untuk memperkuat informasi yang diperoleh melalui angket.

Sasaran wawancara yaitu guru kimia lulusan Program Studi Pendidikan Kimia FMIPA UNY, kepala sekolah dan guru sejawat. Informasi yang diperoleh dari kepala sekolah menunjukkan bahwa rata-rata cara mengajar 


\section{Jurnal Inovasi Pendidikan IPA, 3 (1), 2017 - 69}

Kresni Dwi Jayanti, S. Senam

guru kimia sudah sesuai dengan ketentuan, harapan sekolah dan kurikulum yang berlaku. Selain itu pelaksanaan pembelajaran yang dilakukan oleh guru kimia juga mengalami peningkatan seiring dengan lama waktu bekerja. Pembelajaran di prodi kimia sangat bermanfaat terutama metode pembelajaran kimia, Untuk materi-materi kimia murninya justru banyak yang tidak diajarkan di SMK secara detail, hanya dasar-dasarnya saja, Namun, materimateri kimia murninya tetap bermanfaat sebagai bahan pengayaan,

Informasi yang diperoleh dari guru sejawat hampir sama dengan dari kepala sekolah. Hubungan kerja antara guru kimia dengan warga sekolah terjalin dengan baik. Guru lulusan program studi ini rata-rata mengajar di sekolah sejak berdirinya sekolah tersebut, sehingga mereka mengetahui perkembangan yang ada di sekolah. Pembelajaran yang diperoleh semasa kuliah di Program Studi Pendidikan Kimia UNY sangat bermanfaat bagi mereka dalam mengembangkan potensi dirinya sebagai guru kimia. Saran dari alumni untuk UNY yaitu perlu meningkatkan pelayanan pendidikannya.

\section{SIMPULAN}

Kinerja guru lulusan Program Studi Pendidikan Kimia Universitas Negeri Yogyakarta yang bekerja di sekolah menengah di Yogyakarta diperoleh hasil berikut: (1) Kompetensi pedagogik guru kimia berdasarkan penilaian kepala sekolah, Guru sejawat dan peserta didik menilai sangat baik sebanyak lebih dari $50 \%$ dan lebih dari 40\% Baik; (2) Kompetensi kepribadian guru kimia berdasarkan penilaian kepala sekolah, guru sejawat, peserta didik menilai sangat baik sebanyak lebuh dari 40\% Sangat Baik dan lebih dari 29\% Baik; (3) Kompetensi sosial guru kimia berdasarkan penilaian kepala sekolah, guru sejawat memiliki, peserta didik menilai sangat baik dan baik masing-masing lebih dari 23\%; (4) Kompetensi profesional guru kimia berdasarkan penilaian kepala sekolah, guru sejawat menilai Sangat Baik lebih dari $47 \%$ dan lebih dari 52\% Baik.

Kinerja guru lulusan Program Studi Pendidikan Kimia Universitas Negeri Yogyakarta yang bekerja sebagai guru di sekolah menengah di Yogyakarta berdasarkan observasi menunjukkan kualitas perencanaan 35,3\% Sangat Baik dan $64,7 \%$ Baik, pelaksanaan $41,2 \%$ Sangat
Baik dan 58,8\% Baik, penilaian pembelajaran memiliki kriteria Sangat Baik 64,7\% dan 35,3\% Baik.

\section{DAFTAR PUSTAKA}

Azwar, S. (2010). Tes prestasi: Fungsi dan pengembangan pengukuran prestasi belajar. Yogyakarta: Pustaka Belajar. http://doi.org/1998

Menteri Pendidikan Nasional. Peraturan menteri nomor 16 tahun 2007 tentang standar kualifikasi akademik dan kompetensi guru, Pub. L. No. 16 (2007).

Presiden Republik Indonesia. Undang-Undang Republik Indonesia nomor 20 tahun 2003 tentang sistem pendidikan nasional, Pub. L. No. 20 (2003). Indonesia. Retrieved from

http://sindikker.dikti.go.id/dok/UU/UU20 -2003-Sisdiknas.pdf

Presiden Republik Indonesia. Undang-undang nomor 14 tahun 2005 tentang guru dan dosen (2005). 14. Retrieved from http://www.sjdih.depkeu.go.id/fullText/20 05/14TAHUN2005UU.htm

Sukanti, S., Sumarsih, S., Siswanto, S., \& Widayati, A. (2008). Persepsi mahasiswa program studi pendidikan akuntansi FISE UNY terhadap profesionalitas guru berdasarkan undang-undang guru dan dosen no 14 Tahun 2005. Jurnal Pendidikan Akuntansi Indonesia, 6(2). Retrieved from http://journal.uny.ac.id/index.php/jpakun/ article/view/935

Suparwoto, S., Prasetya, Z. K., Mundilarto, M., Sukardjo, S., \& Projosantoso, A. K. (2010). Evaluasi kinerja guru IPA SD, SMP, SMA se-Propinsi Daerah Istimewa Yogyakarta dan dosen FMIPA Universitas Negeri Yogyakarta pasca sertifikasi. Yogyakarta. Retrieved from http://lppm.uny.ac.id/sites/lppm.uny.ac.id/ files/abstrak_7_2.pdf

Warso, A. W. D. D. (2012). Peningkatan profesionalisme dan kesejahteraan untuk mewujudkan guru non PNS yang sejahtera dan bermartabat. Retrieved from http://lpmpjogja.org 